\title{
"What do cross-country Bitcoin holdings tell us? Monetary and institutional discontent vs financial development"
}

\begin{tabular}{|c|c|c|}
\hline AUTHORS & $\begin{array}{l}\text { Viktor Koziuk (i) } \\
\mathbb{R}\end{array}$ & \\
\hline ARTICLE INFO & $\begin{array}{l}\text { Viktor Koziuk (2022). What do c } \\
\text { and institutional discontent vs fir } \\
\text { and Financial Innovations, } 19(1\end{array}$ & $\begin{array}{l}\text { n holdings tell us? Monetary } \\
\text { nt. Investment Management } \\
21511 / \text { imfi.19(1).2022.13 }\end{array}$ \\
\hline DOI & http://dx.doi.org/10.21511/imfi.1s & \\
\hline RELEASED ON & Monday, 21 February 2022 & \\
\hline RECEIVED ON & Wednesday, 05 January 2022 & \\
\hline ACCEPTED ON & Tuesday, 15 February 2022 & \\
\hline LICENSE & $\begin{array}{l}(\mathrm{ccc}) \mathrm{EY} \\
\text { This work is licensed under a C } \\
\text { License }\end{array}$ & Attribution 4.0 International \\
\hline JOURNAL & "Investment Management and F & \\
\hline ISSN PRINT & $1810-4967$ & \\
\hline ISSN ONLINE & $1812-9358$ & \\
\hline PUBLISHER & LLC "Consulting Publishing Cor & "erspectives" \\
\hline FOUNDER & LLC "Consulting Publishing Cor & "erspectives" \\
\hline $0^{\circ}$ & $B$ & $\begin{array}{l}\text { 三ニ } \\
\text { 三ニ }\end{array}$ \\
\hline NUMBER OF REFERENCES & NUMBER OF FIGURES & NUMBER OF TABLES \\
\hline 51 & 5 & 2 \\
\hline
\end{tabular}

(c) The author(s) 2022. This publication is an open access article. 


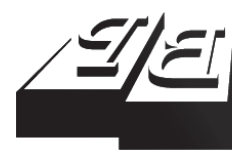

\section{BUSINESS PERSPECTIVES}

(O)

LLC "CPC "Business Perspectives" Hryhorii Skovoroda lane, 10, Sumy, 40022, Ukraine www.businessperspectives.org
Received on: $5^{\text {th }}$ of January, 2022 Accepted on: 15 $5^{\text {th }}$ of February, 2022 Published on: $21^{\text {st }}$ of February, 2022

(C) Viktor Koziuk, 2022

Viktor Koziuk, Doctor of Economics, Professor, Head of the Economics Department at West Ukrainian National University, Ukraine.
This is an Open Access article, distributed under the terms of the Creative Commons Attribution 4.0 International license, which permits unrestricted re-use, distribution, and reproduction in any medium, provided the original work is properly cited.

Conflict of interest statement: Author(s) reported no conflict of interest
Viktor Koziuk (Ukraine)

\section{WHAT DO CROSS-COUNTRY BITCOIN HOLDINGS TELL US? MONETARY AND INSTITUTIONAL DISCONTENT VS FINANCIAL DEVELOPMENT}

\begin{abstract}
Cryptocurrencies show tremendous growth by market capitalization, however Bitcoin cross-country holdings are still in question. The purpose of the paper is to show that inflation discontent with the rule of law failures can explain why residents of different countries are prone to cryptocurrency holdings. The level of financial development is also considered. A hypothesis is proposed for more complex and segmented motives of Bitcoin holdings, tested by the OLS method. Single- and multi-factor regressions with independent variables are used, which can validate cross-country Bitcoin holdings in terms of inflation discontent, quality of institutions and financial development. Regression results confirm the idea of more segmented motives to hold Bitcoins. First, the hedge against inflation motive is rooted in the institutional weakness of central banks, and the regression results show that inflation variables are the most significant. Second, the hedge against institutional risks of asset ownership motive, based on the lack of rule of law and the relevant variable, is best performing among other institutional variables. Third, it is wrong to neglect financial development. However, it only plays a role in interaction with better innovation performance, meaning that crypto investors try not only to diversify their portfolios, but also to profit from involving in a sector with promising technological perspectives. The main takeaway is that institutional factors help explain why people in countries with worsened inflation and institutional performance tend to hold a large fraction of Bitcoins in assets. Obviously, monetary and institutional fragility is underestimated in the general discussion about the nature of digital money.
\end{abstract}

\section{Keywords}

cryptocurrency, central banks, Bitcoin, rule of law, inflation, quality of institutions

JEL Classification

E40, E42, E44, E58, G11

\section{INTRODUCTION}

More than 10 years have passed since the emergence of a new phenomenon - digital money, the ownership and exchange of which is confirmed by block-chain technology. Despite the apparent initial marginalization of radical skepticism and crypto-euphoria, it is becoming increasingly clear that cryptoassets are becoming an integral part of global finance. There is no doubt that the evolution of distributed ledger technology, the further development of cryptocurrency issuance models (for example, the emergence of stablecoins) and the growing amount of programmable money have paved the way for the financial industry and its unprecedented convergence with innovation. The first cryptocurrency, Bitcoin, has become a symbol of a new era of digital transformation.

Despite the obvious technological breakthrough in solving the traditional institutional dilemma of trust in decentralized systems, cryptocurrencies are ambiguous. For many regulators, they pose a risk of technological improvements in antisocial activities. The significant 
volatility of prices for cryptoassets requires caution when legalizing transactions with them by financial institutions under supervision and regulation. The same price volatility significantly limits the potential of cryptocurrencies to perform a well-established set of money functions (this phenomenon is well highlighted in Griffoli et al. (2018)). However, cryptocurrencies have become a specific asset class. It meets certain criteria according to which they become quite attractive to expand the boundaries of the traditional portfolio, such as low correlation with other assets, high profitability at certain time intervals, and going beyond the usual markets. On the other hand, cryptocurrencies have demonstrated the ability to fill both the niche of certain dysfunctions of the existing financial infrastructure and to circumvent regulatory barriers. At the same time, the acceleration of post-Covid inflation and divergent changes in commodity price dynamics have affected the resumption of interest in the analysis of assets for their ability to hedge the risk of currency depreciation. To date, there is a tendency to consider cryptocurrencies as "digital gold". This approach is more in line with the logic of investment choice. But the possibility of using cryptocurrencies in a much broader functional dimension, combined with their ability to perform certain aspects of monetary functions, brings to the fore a more complex problem. Demand for privately issued digital money may reflect not only a way to hedge against inflation, but also a way to adapt to the institutional failures of the current fiat money order, which is based on confidence in the central bank's ability to ensure price and financial stability. The inabilities of monetary authorities to guarantee macrofinancial stability and the distorted redistributive and exploitative/expropriational intentions of the government have a common denominator - institutional quality. It is not surprising that central banks are not more confident as CBDC issuers than privately issued digital money that inflation is higher and more volatile (Koziuk, 2021). Given this, interest in such money may be determined not only by investment motives. Bitcoin and other cryptoassets may embody a new standard for adapting to institutional failures: inflation hedge, making payments outside the regulatory perimeter, protecting property rights, avoiding the risk of property expropriation and others. This raises the question of the factors that determine the cryptoasset ownership across countries.

\section{LITERATURE REVIEW}

The problem of cryptocurrency ownership is at the intersection for many research areas. A number of papers point out that the cryptocurrency ownership is mostly investment in nature with a focus on speculative income. This is emphasized in the relevant analytical reviews and various kinds of surveys.

For example, the OECD (2019) announces that the vast majority of digital money owners from Asia put forward the motive to make quick profits. The possibility of gaining the benefits of programming money or inflation hedge in its purest form is not a priority motive, which is a challenge to a broader view of the prospects for the institutional positioning of privately issued digital money. Similar findings are contained in such other investigations. In the UK, the FCA $(2019,2021)$, analyzing awareness of cryptoasset transactions, the opportunities they offer, and the risks involved in investing in them, concluded that the "fast track to easy wealth" is the dominant motive. Studies with a similar search structure and conclusions about the "portrait" of a retail investor in cryptocurrencies came in the Netherlands (AFM, 2018) and Austria (Ritzberger-Grünwald Stix, 2018). Analysis of the level of financial literacy in cryptocurrency ownership has shown that investors who are more aware of them are less likely to trade with them (Panos \& Karkkainen, 2019).

Such studies generally explain the previously identified conditionality of price dynamics in the cryptoassets market by the degree of interest in them from a wide range of agents: the price correlation and number of search queries. But they do not take into account that the growing role of this asset class in global finance is ahead of the superficial speculative interest of retail investors. However, even such studies indicate a problem of trust, pointing to differences in the origin of cryptoassets in their owners (OECD, 2019). The dominance of assets acquired on the secondary market, rather than during the initial coins offering, indicates that cryptocurrencies that already had previous owners are more trusted, thus confirming the validity of their virtual existence. 
Also, such research does not focus on the broader institutional context of cryptoassets ownership, which may stem from the problem of trust in government institutions and hierarchies. For example, Vaz and Brown (2020) point out that the trust in money is based on a whole set of elements confirming their validity, located in the respective hierarchies.

The problem of trust in money is an important part of explaining why cryptocurrencies may even exist. If no one wanted to own them, they would not spread. However, the biggest problem is why private money are trusted, while the fiat money model with the central bank continues to coexist quite effectively. Thus, Carstens (2018b) points out that if the value of money is not guaranteed intrinsically, it should be guaranteed institutionally through the appropriate positioning of the central bank. Borio (2019) emphasizes that the ability to guarantee price and financial stability is the basis for the synergistic effect between trust and the ability of money to perform its functions in structural integrity, which is not possible without a central bank model. In turn, Schnabel and Shin $(2004,2018)$ emphasize that collective experience is needed to be money as a payment instrument. In fact, the example of collective experience also explains why ownership through the secondary market outweighs ownership through the ICO, as shown in the OECD (2019). And theoretical argumentation from the standpoint of collective experience and money as memory is the basis of the modern view of the nature of money as such (Schnabel \& Shin, 2004; Milgrom \& Stokey, 1982; Kocherlakota, 1996, 1998; Algietta, 2002). At the same time, Koziuk (2021a) shows that economic agents do not perceive CBDC and privately issued digital money as the same asset class. In countries where central banks are more efficient and the inflation experience is less traumatic, trust in the CBDC is little different from trust in cryptocurrencies, but in countries with poorer monetary qualities, privately issued digital money are more trusted.

The heterogeneity of trust in digital money indicates that economic agents perceive them as a different set of drivers of value than the traditional approach to analyzing the functions of money. Many authors clearly articulated that privately issued cryptocurrencies cannot effectively perform the functions of money in their structural integrity (Carstens, 2018a; Griffoli et al., 2018; Bauretal, 2018). Price volatility is a key factor in why unit of account undermines medium of exchange, even if store of value can operate within a certain platform trust or self-affirmation through multiple decentralized interactions of economic agents. It follows that the dominance of investment motives should be decisive, which, in fact, is confirmed by studies based on surveys (OECD, 2019; FCA, 2019, 2021).

The investment motive for cryptocurrencies ownership is quite logical, given that their role in securing mass payments is limited. It is in the context of investment analysis that studies have been developed to explain the behavior of cryptocurrency prices, especially Bitcoin. Initially, significant emphasis was placed on the analysis of high price volatility and non-correlation with market assets (Yermack, 2015; Liuand Tsyvinski, 2018). An alternative approach is presented in studies based on the analysis of the Bitcoin value and other cryptocurrencies for "network externalities" and Metcalfe's Law. Such surveys confirm that the number of new wallets created can be considered as an explanatory factor in the market value of Bitcoin (Peterson, 2018; Van Vliet, 2018). Stylianov et al. (2021) show that for cryptocurrencies, "network effects", namely high market concentration, early entry benefits, and barriers to entry, do not work fully. In particular, the low level of concentration in the cryptoassets market and the lack of impact of the concentration factor on competition between cryptocurrencies suggests that the market value of Bitcoin and other currencies cannot be fully explained on the basis of the "network effect" approach. In turn, Aste (2019) points to the need to take into account the "network effects" and the mood of the participants of such a network when analyzing the prices of cryptocurrencies, including Bitcoin. Changes in sentiment and prices are mutually influenced, which significantly distinguishes cryptoassets from other asset classes.

If the results of Aste (2019) are consistent with the conclusions about the investment-speculative motive of cryptocurrency ownership, in particular, in terms of sensitivity of market prices to player attitudes inherent in the behavior of retail inves- 
tors, the results of Stylianov et al. (2021) are ambiguous in the context of market concentration. Theoretically, regulatory barriers, non-regulatory positioning of cryptocurrencies and the specific value for their holders support the assumption that there should be a low concentration of ownership in this market. Therefore, the growing role of institutional investors with more sophisticated trading strategies (IMF, 2021) suggests that the concentration of the cryptocurrency market should increase. The effects of concentration are important not only for understanding the processes of value formation and the dominant influence on price by players with a stronger market position. In a more concentrated market, the integration of cryptocurrencies with a more developed financial system is obviously more important. In other words, the more developed the financial system is, the more institutional investors are willing to take on the additional risk of market volatility, also expecting benefits from operating in a market associated with innovative financial technologies. Lower concentrations should indicate that cryptoassets ownership is determined by the specific value they provide to holders. This means that cryptocurrency ownership may stem from the need to hedge against inflation and institutional risks.

This view of the problem is based on research that perceives the emergence of "digital gold" in cryptocurrencies. Thus, the specificity of gold as an asset class is based on the fact that it does not have the risk of default, it is not a requirement against assets backed liability, it embodies intrinsic value (Zulaica, 2020). Despite the controversy over whether gold serves as a "safe asset" (Bauer \& Mc Dermontt, 2010; Dar \& Mairta 2017), there is evidence that it is a natural toolkit for hedge against monetary and geopolitical tensions (Reboredo, 2013; Conover et al., 2009; Zulaica, 2020). Accordingly, the value of Bitcoin and other cryptocurrencies should be associated with monetary shocks.

However, empirical research is ambiguous in this regard, in particular, in the aspect that the response of market prices of Bitcoin does not follow the standard algorithm of response to the actions of central banks. A number of studies emphasize that the motives for Bitcoin ownership are similar to the investment motives for exposures in pre- cious metals (Dyhrberg, 2016; Halaburda, 2020). There are signs in the behavior of cryptocurrency prices that they can be used to hedge against inflationary shocks and financial stress (Corbet et al., 2020; Bouri, Molnár et al., 2017). Similarly, geopolitical risks affect the market value of cryptocurrencies, thus emphasizing their role as the digital equivalent of "safe havens" (Smales, 2019; Corbet et al., 2020; Bouri, Gupta et al., 2017; Bouri, Molnár et al., 2017).

In contrast to research focusing on the portfolio properties of cryptocurrency investments and related drivers of their market value, Karau (2021) points to a fundamentally different problem. The identification of Bitcoin with "digital gold" is not entirely correct. It is much better to compare it with a vehicle currency, or "global digital cash", which immediately hedge against inflation, vulnerabilities of the financial sector to shocks, as well as the possibility of "overflow" from jurisdiction to jurisdiction outside formal regulatory barriers. In particular, Karau (2021) points out that the price of Bitcoin responds to the shock in the euro area as if cryptocurrency is an instrument of hedging against inflationary shock (hawk signal lowers its price), and in the case of the Fed's hawk signal the situation is different - the price of Bitcoin rises. That is, in the case of the pair "EuroBitcoin" the effect of inflation hedge is observed, which is close to the effect of "digital gold", and in the case of the pair "Dollar-Bitcoin" this effect is no longer observed. According to Karau (2021), the main reason for this is that the demand for Bitcoin demonstrates the response to the risks of deteriorating financial conditions in the emerging markets by exiting more risky assets and "overflow" into cryptocurrency. This reinforces the theoretical position that when the vulnerability of the economy is due to the institutional weakness of monetary power, cryptocurrencies take over the role of dollarization (Cifuentes, 2018). Naturally, the institutional analysis of money cites dollarization as a typical example of the problem of trust in the central bank in the narrow sense and power in the broad sense. Lack of confidence in the ability of money to perform the relevant functions pushes economic agents to foreign exchange substitution (Gomez, 2019). Bitcoin has a clear advantage in this aspect, as it also allows transactions and shadow cross-border capital flows. 
Nevertheless, the portfolio approach to analyzing the motives of Bitcoin ownership limits the ability to identify the importance of institutional factors. After all, as shown in a number of studies, inflation is a manifestation of the lack of institutional quality, particularly in the difference between formal and de facto independence of the central bank (Nurbayev, 2017; Moser, 1999; Keeper \& Stasavage, 2003; Hayo \& Voigt, 2008).

This paper is based on the assumption that the structural characteristics of a country can explain the motives for cryptocurrency ownership. Motives for hedging against institutional and monetary policy risks may dominate. However, taking into account the growing importance of cryptocurrencies in global finance (IMF, 2021), as well as the growing volume of literature on the role of cryptoassets in portfolio diversification (Dyhrberg, 2016; Bouri, Gupta et al., 2017, Bouri, Molnár et al., 2017), it should not be rejected that financial development may play a separate role. The level of development of the financial system may also determine the share of the population that owns Bitcoin, but not so much for reasons to hedge against institutional or inflation risks, but for the reasons of expanding the market portfolio and reaping the benefits of investing in assets associated with technological innovations.

The purpose of the paper is to test empirically the idea that cross-country Bitcoin holdings could be determined by complicated and segmented factors defined as monetary order discontent and institutional weakness. Financial development as a precondition for sophisticated investment strategies is also considered.

The hypothesis is the following. While higher inflation and lack of property rights may demonstrate weaker institutions and fragile central banks, economic agents are forced to hold larger fraction of assets in cryptocurrency to hedge against inflation and expropriation risks. At the same time, the level of financial development may affect the motivation to hold Bitcoins from the sophisticated portfolio management point of view. Thus, financial development is considered among institutional discontent factors as a separate driver of cryptoasset holdings and should be in a direct relationship with Bitcoin holdings.

\section{BITCOIN: EVIDENCE OF CRYPTOASSET CAPITALIZATION AND MARKET PRICING}

The appearance of DLT technology is clearly revolutionizing global finance, paving the way for the development of programmable money, a breakthrough in payment services and the further convergence of finance and innovation. Cryptocurrencies have opened up the possibility of integrating the technological way of solving the trust dilemma in decentralized systems with new ways of creating value for consumers of financial services. At the same time, the scale of potential changes in payment technologies began to be seen almost as an alternative to the existing monetary order with a view of undermining the key role of central banks in it. However, in the initial version, cryptocurrencies showed a rather limited ability to function as money in their structural integrity, and the technological features of the distributed registry called into question early enthusiasm that a DLT-based payment system could be built, taking into account transaction speeds and energy costs.

On the one hand, this problem did not reject the idea of developing block-chain payment services, but, on the contrary, it encouraged innovation in the field of cryptocurrencies, increasing competition between them. The practical implementation of the idea of programmed money, stablecoins and related solutions in the field of financial services has established the role of cryptocurrencies in the global financial landscape. On the other hand, cryptocurrencies have very quickly become cryptoassets, retaining the ability to meet the needs of payments, asset management, and hedging against institutional and monetary risks at the same time. The behavior of cryptocurrency prices has shown that what does not make them money in the traditional sense of the word. turns them into an asset with a special investment profile. It is no coincidence that the market capitalization for cryptoassets has an obvious upward trend (Figure 1) (IMF, 2021).

Despite significant fluctuations in market capitalization, the emergence of new types of cryptoassets improves the market position as a whole, more prominently reflecting the leadership positions of such 


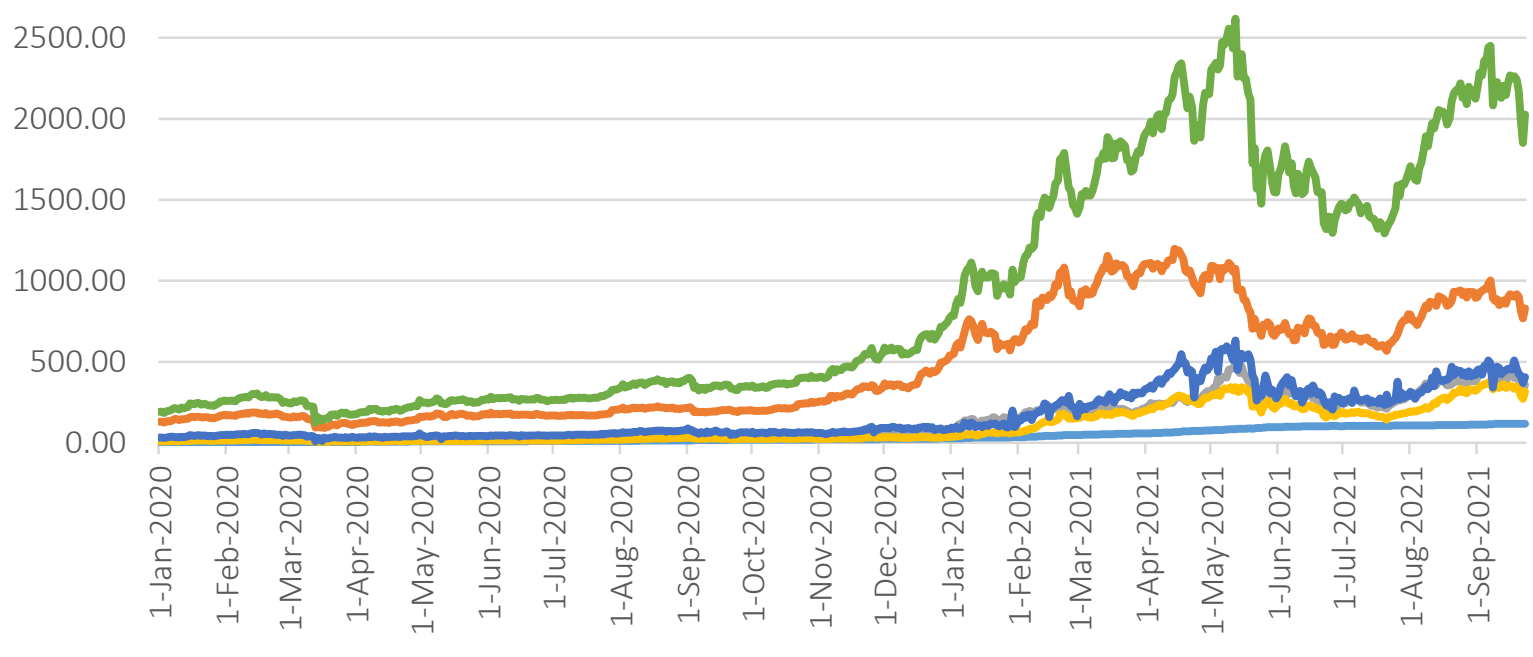

Stablecoins $\longrightarrow$ Bitcoin $\longrightarrow$ Ether $\longrightarrow$ Smart contract ex. Ether $\longrightarrow$ Other

Figure 1. Market capitalization for cryptoassets, USD bln

solutions as Bitcoin. Figure 1 shows that until the beginning of 2021, market capitalization for cryptoassets was largely determined by the capitalization of Bitcoin. In that time, the role of this cryptocurrency is weakening. Market capitalization as a whole began to be subject to a wider range of individual market segments. However, the role of Bitcoin still remains significant.

It remains an open question whether the success of cryptocurrencies is due to changes in mon- etary policy since the global financial crisis, or whether it reflects the spontaneity of innovation. Nevertheless, the allocation of cryptocurrencies to a separate asset class, which has occupied a certain investment niche in portfolio management, is largely due to the fact that the behavior of prices, including Bitcoin, there is certain sensitivity to the effects of global liquidity expansion.

Figure 2 shows that in the medium term, there are no clear and convincing signs of an inverse rela-

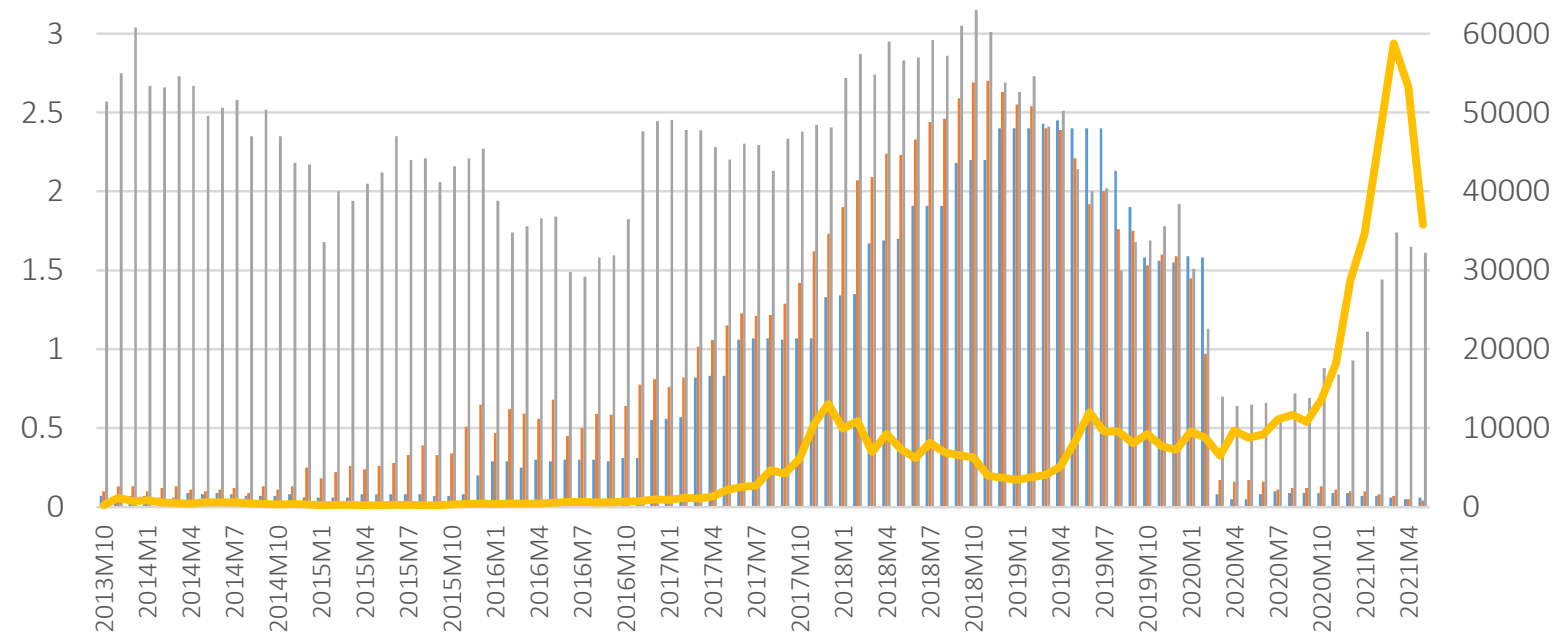

Federal funds rate 1 1Y T-Bills 10 Y T-Bills $\longrightarrow$ Bitcoin (BTC) price index in U.S. dollars

Figure 2. Bitcoin and US interest rates 


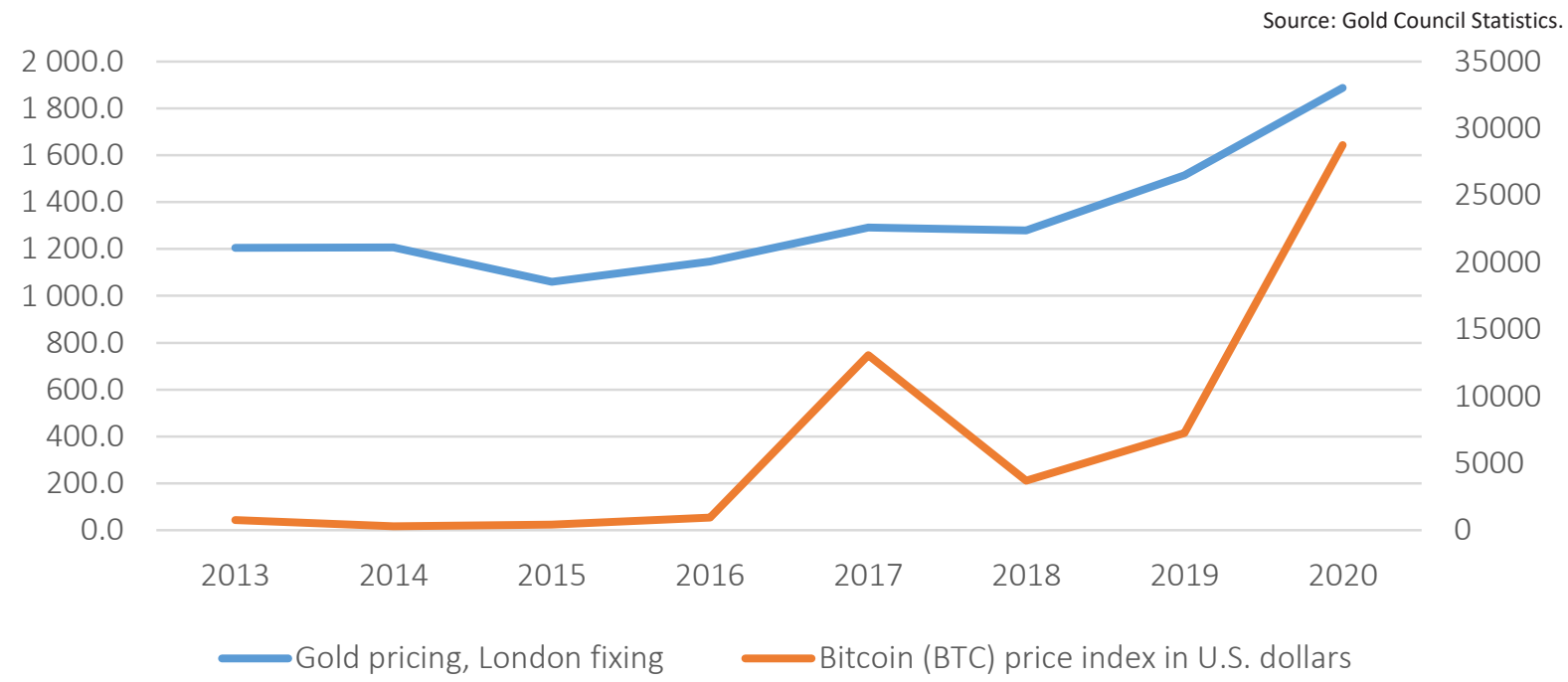

Figure 3. Gold and Bitcoin pricing

tionship between the market value of Bitcoin and global monetary conditions expressed in US capital market rates. However, since 2020 the situation has changed.

Figure 2 shows that Bitcoin price extremes until 2020 were not related to changes in the time structure of interest rates in the US market. Moreover, in 2017, the jump in Bitcoin prices took place against the background of monetary conditions, which became more stringent, and in 2019 it was the other way around. The lack of a clear relationship between the movement of monetary conditions and Bitcoin prices complicates its positioning as a toolkit for hedging against inflationary shocks. But in 2020 the situation has changed. The sharp jump in Bitcoin prices was accompanied by a significant difference between short- and long-term rates in the US market. This episode accurately characterizes the association of Bitcoin with "digital gold", as long-term rates have already begun to respond to accelerating inflation in the US and around the world, while short-term continued to be influenced by monetary expansion by the Fed. This effect can be seen in the example of commodity and gold prices, which are known to respond quite clearly to the expansion of global liquidity (Bauer \& McDermontt, 2010; Dar \& Mairta, 2017; Reboredo, 2013; Conover et al., 2009; Zulaica, 2020). The data in Figure 3 also confirm that in the medium term, gold and Bitcoin pricing show signs of strong correlation, especially in times of upward pressure.
In contrast to the relatively well-traced correlation between Bitcoin and gold pricing, the correlation between the former and commodity prices is less obvious (Figure 4). In the medium term, local peaks in cryptocurrency and commodity prices coincided only once in 2017. In general, this weakens the argument that Bitcoin prices are a consequence of global liquidity expansion, to which, in turn, commodity prices are quite sensitive. However, in 2020 the situation has changed. There is a strong upward pressure in both markets. In conjunction with the data in Figures 2 and 3, this may indicate that the cryptocurrency market has begun to receive liquidity created by soft monetary conditions in the United States in response to overcoming the effects of the crisis. This does not contradict but rather confirms the hypothesis that soft monetary conditions encourage the flow of capital to higher-risk asset markets, and is consistent with the well-known empirical evidence that soft monetary policy in the United States is a global driver of capital flows in direction toward yield-seeking (Miranda-Agrippino \& Rey, 2020; Miranda-Agrippino \& Ricco, 2021).

The reaction of cryptocurrency prices to the easing of global monetary conditions, although it may reflect signs of positioning as digital gold, rather confirms how risky this asset is. Figure 5 demonstrates that cryptoassets have shown the highest level of risk-adjusted returns over the past year.

Together, Bitcoin and the 10 most popular cryptoassets have shown a fairly high propensity for 


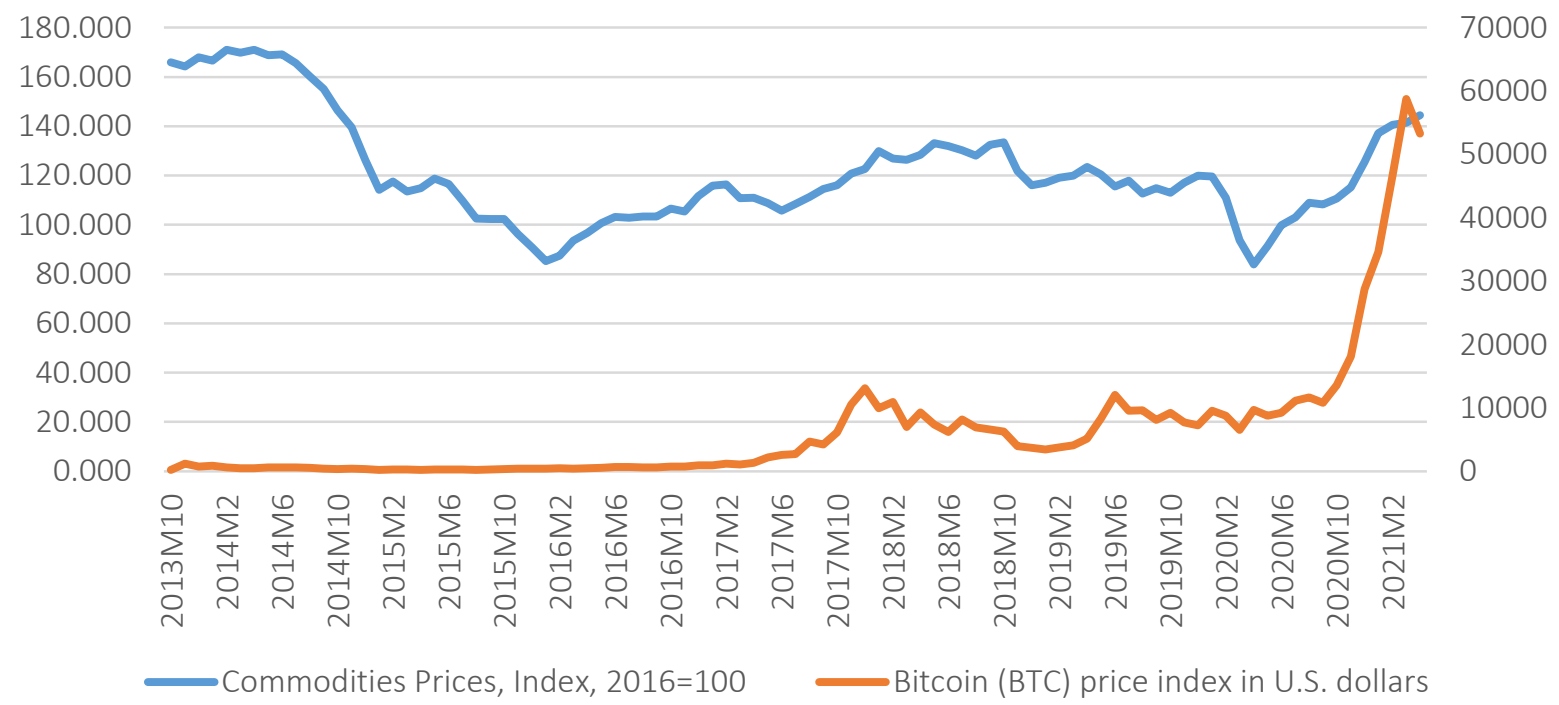

Figure 4. Commodity price index and Bitcoin

volatility. The reason why the yield and volatility in the market in cryptoassets have increased over the last year can be explained by the fact that accelerating inflation and signals from leading central banks to normalize monetary policy have turned out to be divergent. Karau (2021) shows that the market value of Bitcoin responds to monetary surprises, even if the reaction to the Fed and the ECB differs. In the first case, the price of Bitcoin is rising as a manifestation of changes in capital flows in response to expectations of a negative impact of tighter monetary policy in the United States on financial conditions in emerging markets. And in the second case, it is a standard reaction to lower prices in response to expectations of tighter monetary conditions in Euros. Such dual effect allows Karau (2021) to announce that Bitcoin behaves more like "global digital cash" than "digital gold". This effect is extremely important for testing the hypothesis in this paper. The vulnerability of financial systems in many countries to changes in global macrofinancial conditions is institutional in nature, as are problems with controlling inflation. They are a consequence of the institutional weakness of central banks. In terms of unique technological properties, Bitcoin ownership can allow you to hedge against monetary and institutional risks and at the same time be a manifestation of a market portfolio expansion strategy.

Source: IMF (2021).

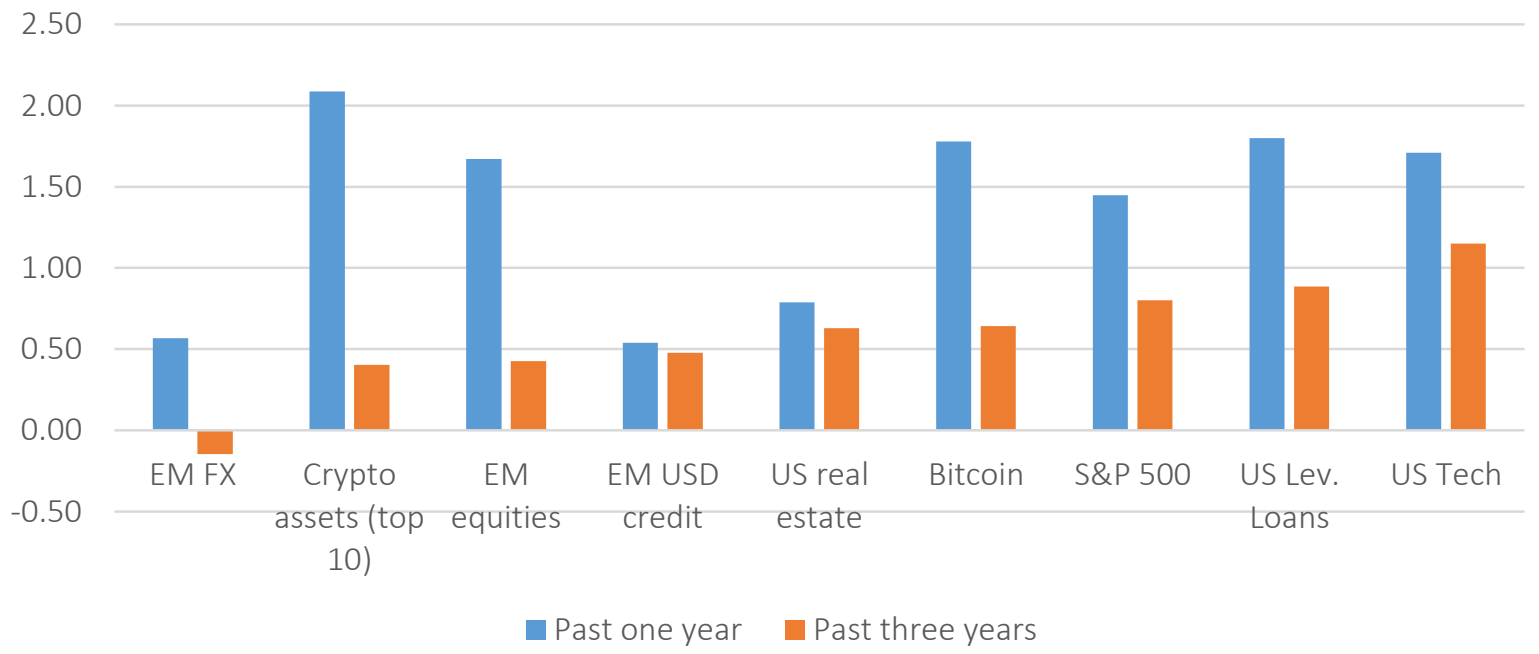

Figure 5. Risk-adjusted returns 


\section{RESEARCH METHODOLOGY}

Empirical testing of hypotheses is based on the method of constructing one- and multi-factor regression equations. The choice of this particular approach is due to a number of reasons. The limited data and their mostly structural nature are the most important. A similar approach has been used to analyze the relationship between the central banks' progress in implementing CBDC and a country's structural characteristics (Auer et al., 2020). An identical method was also used to analyze the relationship between the depth of central banks' progress in the implementation of CBDC projects and their independence in combination with other structural characteristics of a country (Koziuk, 2021).

The set of explanatory variables was chosen in such a way that one could see the consistency and inconsistency between them and the indicator that characterizes the Bitcoin ownership across countries. The number of countries is 139 , covering different developed, emerging and developing countries. Accordingly, the dependent variable is the share of the population that owns this cryptocurrency (Global Cryptocurrency Ownership Data, 2021, triple-a.io/crypto-ownership/).

The independent variables are as follows:

- Financial Development Index (FinDev). This index characterizes the degree of financial development of a country in terms of market depth, the scale of financial institutions and the availability of financial services (Svirydzenka, 2016). Given that the level of financial development correlates with the level of well-being, the majority of people who prefer to own risky assets indirectly confirm the position of a direct relationship between well-being and risk appetite. It should be noted that the hypothesis of the conditionality of Bitcoin ownership by the level of financial development of a country is confirmed if there is a direct relationship between this variable and the dependent variable. If the connection is weak or inverse, this hypothesis should be considered unconfirmed.

- Global Innovation Index (GlobInn). This variable is designed to enhance understanding of the conditionality of the propensity to Bitcoin ownership for reasons of financial development given the steady trend towards convergence of finance and innovation. In addition, the more innovation developed in a country, the more likely it is that the range of experts in DLT solutions will be wider. Bitcoin ownership may also indicate a desire to be involved in promising technological solutions in the field of finance. Therefore, a direct relationship should be theoretically predictable, as should be the case with the Financial Development Index.

- Index of Central Banks' Progress in CBDC projects $(C B D C)$. Certain structural characteristics of a country, such as the level of the shadow economy or the volume of currency in circulation, determine the interest of central banks in promoting the idea of a centralized alternative to privately issued cryptocurrencies (Auer, 2020), and therefore it may have indicative content imperfections of fiat money in a country. However, in the analysis of this variable, it is not assigned a key role, but rather an auxiliary one.

- Index of Economic Freedom (EcFr). The lower the economic freedom in a country, the more motives for cryptocurrency transactions. Similarly, the indices of monetary freedom (MonFr) and financial freedom (FinFr) are used alongside the general Index of Economic Freedom. They specify the constraint on economic activity, and therefore complement the overall impact of the institutional parameter as economic freedom in favor of Bitcoin ownership and can potentially help to understand which of the barriers to economic activity is more significant. For example, one that is related to the overall institutional nature of the burden of constraints, or one that stems from the money transaction or access to finance sector.

- Chinn-Ito Index (ChinnIto). As cryptocurrencies allow cross-border transactions outside the usual regulatory perimeter, the nature of restrictions on capital flows may determine the need to have instruments that will ensure the transfer of funds across national borders. This index traditionally assumes that a greater 
value characterizes fewer restrictions on capital flows, and therefore, theoretically, an inverse relationship should be expected.

- Rule of Law Index (RofL). Theoretically, the reverse relationship would be correct, as the motives for owning an asset that is not subject to restrictions by government institutions are a reflection of how economic agents hedge against relevant risks.

- Burden of Government Regulation Index (BofGR). Like the Rule of Law Index, it is calculated by the World Bank, but unlike the former, is not always interpreted unambiguously. For example, the greater burden of regulation may be the result of a society's choice of more interventionist policies, and may be a manifestation of inefficient government expansion. It can be assumed that the greater burden of regulation should encourage a greater propensity to cryptocurrencies ownership.

- Inflation. It directly indicates the extent to which economic agents are dissatisfied with the monetary order of fiat money and are willing to hedge against the weak institutional framework of central banks through the placement of assets in cryptocurrencies. Inflation in the regression analysis is represented by three variables. Ln of average inflation 2000-2020 (Infl 00-20) is to identify medium-term drivers of dissatisfaction with the current monetary order. Ln of average inflation 2010-2020 (Infl10-20) is to track the impact of inflation on the choice of economic agents during the expansion of cryptocurrencies. Ln of standard deviation of inflation 2000-2020 is to indicate the degree of instability in monetary policy, which affects the dissatisfaction of economic agents with the performance of money as a unit of account. Logarithmization applied in order to normalize the data series and eliminate distortions due to hyperinflationary episodes in some countries. The example of Venezuela is the most illustrative, as the country has the highest inflation in the world in recent times and the highest level of sharing of cryptocurrencies. Naturally, a direct relationship between the analyzed variables would be theoretically correct.
In general, the results of regression analysis confirmed the logic of the selected variables for testing the stated hypotheses, which is reflected in the following parts of the paper.

\section{EMPIRICAL RESULTS}

As already mentioned, the empirical technique of analysis is based on a separate construction of single- and multi-factor regression models (Tables 1 and 2). In general, the obtained parameters of single-factor models testify to the existence of theoretically predictable directions of a relationship.

The results presented in Table 1 demonstrate that all the selected variables are related to the share of the population that owns Bitcoin (across countries), the direction of which corresponds to theoretical assumptions. However, a single-factor analysis shows that the most statistically significant relationship is found in variables such as the Financial Development Index, the Global Innovation Index, the Monetary Freedom Index and indicators of inflation volatility. Similarly, the statistical significance and direct relationship can be traced to a variable that characterizes the central banks' progress in preparing for the introduction of the CBDC. Nonetheless, institutional variables and the degree of liberalization of capital flows have not shown sufficient statistical significance, although the direction of the relationship is correct. Nevertheless, in all these cases, the density relationship is quite low. In general, the results of a single-factor analysis allow us to conclude that, despite the general validity of the hypotheses, none of the variables alone can reliably explain the differences in the choice in favor of Bitcoin ownership across countries. One can only speculate that most likely a combination of factors will better explain the share of cryptocurrency ownership. However hypotheses about the role of financial system development and hedging against monetary risks are more likely to be confirmed.

The results presented in Table 2 confirm that the combination of factors allows explaining the choice in favor of Bitcoin ownership correctly. It is noteworthy that the inclusion of all variables in the structure of the regression model leads 


\begin{tabular}{|c|c|c|c|c|c|c|c|c|c|c|c|c|}
\hline \multicolumn{13}{|c|}{ Source: Calculated by the author using the Statistica software package. } \\
\hline & $(1)$ & (2) & (3) & (4) & (5) & (6) & (7) & (8) & (9) & (10) & (11) & $(12)$ \\
\hline \multirow{3}{*}{ FinDev } & 2.391 & & & & & & & & & & & \\
\hline & (3.193) & & & & & & & & & & & \\
\hline & 0.002 & & & & & & & & & & & \\
\hline \multirow{3}{*}{ GlobInn } & & 0.039 & & & & & & & & & & \\
\hline & & $(2.554)$ & & & & & & & & & & \\
\hline & & 0.012 & & & & & & & & & & \\
\hline \multirow{3}{*}{ CBDC } & & & 0.766 & & & & & & & & & \\
\hline & & & $(3.548)$ & & & & & & & & & \\
\hline & & & 0.001 & & & & & & & & & \\
\hline \multirow{3}{*}{ EcFr } & & & & -0.007 & & & & & & & & \\
\hline & & & & $(-0.382)$ & & & & & & & & \\
\hline & & & & 0.703 & & & & & & & & \\
\hline \multirow{3}{*}{ MonFr } & & & & & -0.068 & & & & & & & \\
\hline & & & & & $(-2.915)$ & & & & & & & \\
\hline & & & & & 0.004 & & & & & & & \\
\hline \multirow{3}{*}{ FinFr } & & & & & & -0.001 & & & & & & \\
\hline & & & & & & $(-0.101)$ & & & & & & \\
\hline & & & & & & 0.920 & & & & & & \\
\hline \multirow{3}{*}{ Chinnlto } & & & & & & & -0.112 & & & & & \\
\hline & & & & & & & $(-0.815)$ & & & & & \\
\hline & & & & & & & 0.417 & & & & & \\
\hline \multirow{3}{*}{ RofL } & & & & & & & & -0.392 & & & & \\
\hline & & & & & & & & $(-0.280)$ & & & & \\
\hline & & & & & & & & 0.780 & & & & \\
\hline \multirow{3}{*}{ BofGR } & & & & & & & & & -0.443 & & & \\
\hline & & & & & & & & & $(-1.565)$ & & & \\
\hline & & & & & & & & & 0.120 & & & \\
\hline \multirow{3}{*}{ Infl00-20 } & & & & & & & & & & 0.468 & & \\
\hline & & & & & & & & & & $(2.913)$ & & \\
\hline & & & & & & & & & & 0.004 & & \\
\hline \multirow{3}{*}{ Infl10-20 } & & & & & & & & & & & 0.476 & \\
\hline & & & & & & & & & & & $(3.324)$ & \\
\hline & & & & & & & & & & & 0.001 & \\
\hline \multirow{3}{*}{ StDevinfl } & & & & & & & & & & & & 0.293 \\
\hline & & & & & & & & & & & & $(1.937)$ \\
\hline & & & & & & & & & & & & 0.055 \\
\hline Intercept & 1.502062 & 1.139489 & 2.060656 & 2.837754 & 7.474631 & 2.442491 & 2.474725 & 2.795202 & 3.935106 & 1.702279 & 1.825710 & 2.005063 \\
\hline$R^{2}$ & 0.071 & 0.052 & 0.092 & 0.00108059 & 0.05921126 & 0.00007541 & 0.005084 & 0.00066738 & 0.018925 & 0.05832233 & 0.074623 & 0.02664725 \\
\hline F statistics & $\begin{array}{c}F(1.134)= \\
10.194\end{array}$ & $\begin{array}{l}F(1.120) \\
=6.5241\end{array}$ & $\begin{array}{c}F(1.124)= \\
12.589\end{array}$ & $\begin{array}{c}F(1.135)= \\
0.14604\end{array}$ & $\begin{array}{c}F(1.135)= \\
8.4966\end{array}$ & $\begin{array}{c}F(1.134)= \\
0.01011\end{array}$ & $\begin{array}{c}F(1.130)= \\
0.66433\end{array}$ & $\begin{array}{c}F(1.117)= \\
0.07814\end{array}$ & $\begin{array}{c}F(1.127)= \\
2.4499\end{array}$ & $\begin{array}{c}F(1.137)= \\
8.4850\end{array}$ & $\begin{array}{c}F(1.137)= \\
11.048\end{array}$ & $\begin{array}{c}F(1.137)= \\
3.7506\end{array}$ \\
\hline
\end{tabular}


to a number of points that need attention. First, the role of the Rule of Law Variable is growing sharply. It becomes the most statistically significant in specifications (1) and (2). The same applies to the variable level of innovation development. Similarly, the relationship between the degree of progress central banks have made in introducing central bank digital currency and the spread of Bitcoin ownership has been confirmed. However, as the analysis of the relationship between these variables is not considered causal but reference, the CBDC score variable is subsequently excluded from the analysis. Second, a number of variables in specifications (1) and (2) change the direction of the relationship, although in single-factor equations this direction is fully consistent with theoretical assumptions. For example, inflation volatility has shown some instability in the direction of the relationship. The same applies to the burden of regulation.

Despite the significant increase in density relationship in the first two specifications, it was later decided to test hypotheses of the motives for Bitcoin ownership by narrowing the number of variables based on analytical assumptions, as well as the stability of the direction of the relationship. Accordingly, the following specifications did not take into account CBDC score variables, monetary and financial freedom indices (in particular, due to the impact of inflation on the value of the first index and the weak statistical significance of the second), the Burden of Government Regulation Index, and inflation volatility and inflation 2000-2020. Only one inflation variable was left for analysis, which covers the period of Bitcoin expansion, i.e. which reflects the actual motive for hedging against monetary risks, and not the habit of attitude to inflation, which can be evidenced by the inflation result in twice the time interval. The hypothesis of the role of financial development in the context of innovation as a factor in cryptocurrency ownership was additionally tested to expand the investment portfolio by entering an asset with a promising innovation component based on the interaction of variables of the Financial Development Index and the Global Innovation Index. This is appropriately reflected in specifications (3) to (9), which completely change the vision regarding the statistical reliability of regression equations.
Based on the data analysis in Table 2, the following conclusions can be drawn.

First, inflation proved to be the most stable and statistically significant factor explaining the choice in favor of Bitcoin. It can be concluded in advance that monetary risks are too underestimated when it comes to choosing to privately issued cryptocurrencies.

Second, financial development is not a factor that can fully explain Bitcoin ownership. Only in specification (5) does the statistical significance of the relationship become acceptable when the factor of the level of innovation development is not taken into account. At the same time, the Global Innovation Index more convincingly corresponds to the share of the population that owns Bitcoin.

Third, because the development level of the financial system and innovation may not coincide, and the idea of the role of financial depth is difficult to reject, given the changes in perceptions of the role of cryptoassets in market portfolios, an additional variable was applied. It is the combination of financial development and innovation that allows one to see how the choice in favor of Bitcoin stems from the expansion of ideas about an effective asset portfolio. Specifications (7) and (8) clearly prove this, demonstrating the unambiguous statistical significance of this variable.

Fourth, without dismissing the assumption that cryptocurrency ownership may stem from restrictions on cross-border capital transfers, the Chinn-Ito Index variable was introduced in specifications (8) and (9). In specification (8), the case of financial development was tested in conjunction with the dissemination of innovation, and in the case of specification (9) this factor was no longer taken into account, but financial development and dissemination of innovation appeared as separate variables. In both cases, the direction of a relationship is theoretically correct, but not statistically significant. In other words, restrictions on capital flows are not a key motive for cryptocurrency ownership. Rather, the existence of such constraints is the result of the level of development of the financial system itself, which is influenced by institutional quality and monetary instability. 
$\vec{\infty} \quad$ Table 2. Multi-factor regression analysis results

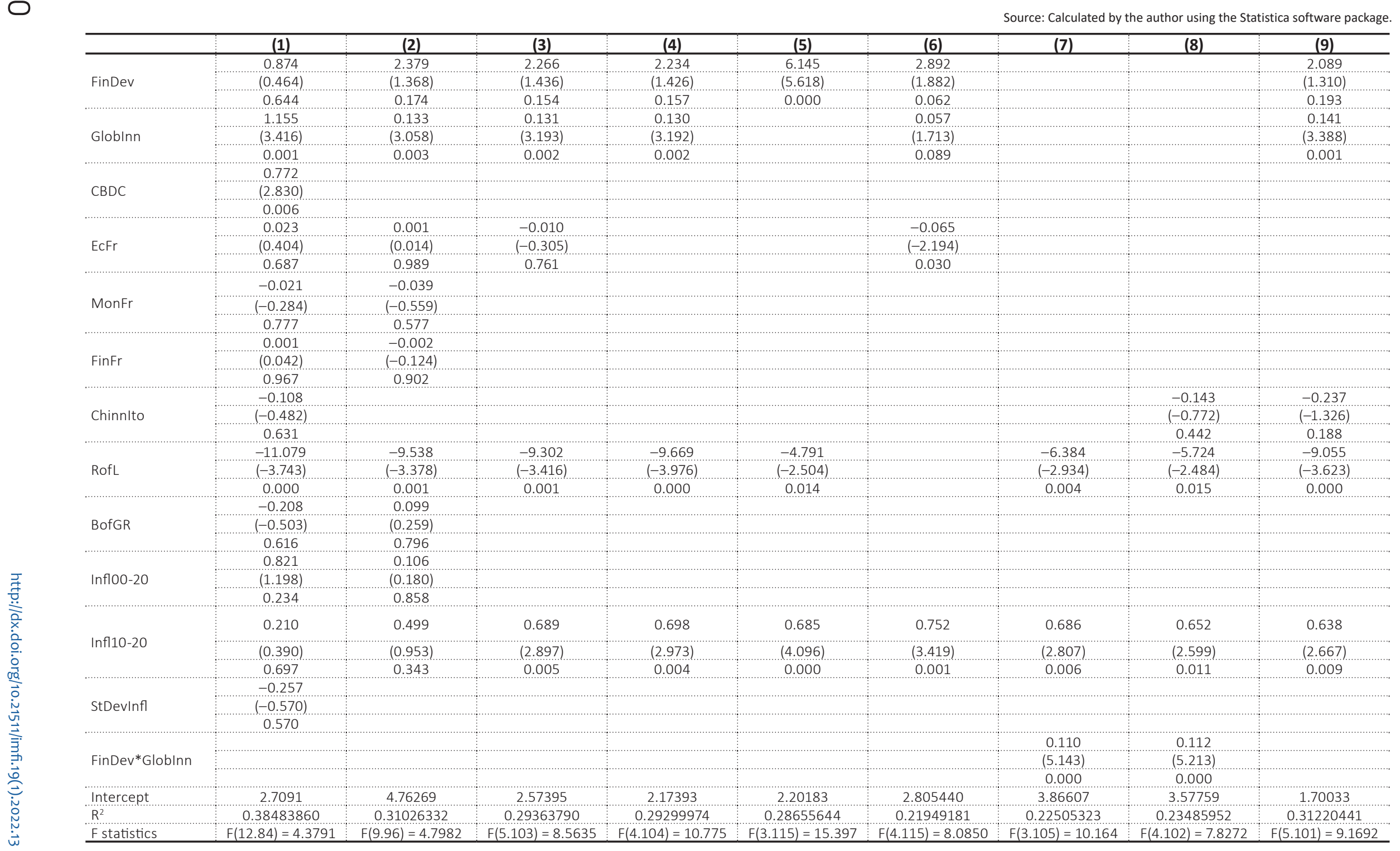


Fifth, the quality of institutions is a defining institutional parameter that explains the choice in favor of asset such as cryptocurrency. At the same time, not surprisingly, the economic freedom represented by the relevant index, neither in the specification with the Rule of Law Index (3), nor in the specification without it (6), does not reach the appropriate statistical significance. Interestingly, without the Rule of Law Index, but with the Index of Economic Freedom, the statistical significance of financial development and the spread of innovation also deteriorate. This pattern can be explained by the fact that the degree of liberality of doing business is not a criterion by which economic agents assess the degree of riskiness of the institutional environment. The choice in favor of a virtual asset is much more determined not by the liberality of business conditions, but by the protection of rights, which reflects the statistical significance of the relationship in the case of the Rule of Law Index. At the same time, the Rule of Law Variable demonstrates the greatest importance in all specifications of multi-factor equations. In this, it is even ahead of the inflation variable. This is in stark contrast to the case of single-factor equations, when the Rule of Law Index did not show sufficient statistical significance.

Sixth, the differences in the significance of the Rule of Law Variable in single- and multi-factor models suggest a more complex vision of the role of institutional quality in determining the choice in favor of cryptoassets ownership. In general, it can be assumed that the rule of law acts both directly through the channel of institutional risks of protection of rights, and indirectly through the channel of institutional guarantees of the reliability of the monetary order for the issuance of fiat money by the central bank. Therefore, as shown in a number of studies (Nurbayev, 2017; Moser, 1999; Keeper \& Stasavage, 2003; Hayo \& Voigt, 2008), trust in the central bank as an issuer of fiat money is impossible without a solid institutional basis.

\section{DISCUSSION}

The empirical results obtained allow us to continue the discussion about the motives for cryptocurrency ownership. The view of Bitcoin as "digital gold" or "global digital cash" has traditionally been clearly underestimated in the context of the fact that the more the network of cryptocurrency transactions expands, the more its owners get new opportunities to meet demand for an asset that simultaneously performs the function of a means of payment and a cross-border funds transfer. The conditionality of Bitcoin ownership in terms of inflation and the institutional quality strengthens the position expressed by Karau (2021) on the specific increase in demand for Bitcoin in lower-income countries in response to the hawk's bias in US monetary policy. In other words, given the risks of financial shock, which in less developed countries is more likely to provoke higher inflation, devaluation and financial instability, "slipping" into an asset that still allows for cross-border transactions may be considered a rational choice.

Koziuk (2021b) noted that trust in centralized and privately issued digital currencies differs in terms of inflationary experience and monetary confidence. The results of the paper confirm that, despite progress in reducing inflation in many countries, economic agents continue to look for toolkits to inflation hedge precisely in the context of how sustainable they view the institutional framework for central bank price stability credentials. Koziuk (2021b) also found that the level of innovation development does not affect trust in digital money. Whereas, this paper shows that the level of innovation is still a factor that determines cryptocurrency ownership. From a formal point of view, there is some contradiction in this. However, it can be explained by the segmentation of the level of information asymmetry and the cognitive barrier in operations with the attributes of the virtual world.

The institutional quality is also underestimated as a factor that encourages economic agents to see in cryptocurrencies the ability to meet needs that cannot be met within centralized fiat monetary systems. The lack of depth in the financial sector, its weak resistance to shocks is one aspect of this phenomenon. Risks of asset expropriation are another dimension of the institutional weakness. At the same time, insisting solely on the hypothesis of "global digital cash" seems a bit exaggerated. Table 1 and 2 show that the factor of formal restrictions on cross-border transactions does not play a significant role. Consequently, the tightness of restrictions on capital flows is not a determining factor 
in Bitcoin ownership, while Lyons and ViswanathNatraj (2020) demonstrate that cryptocurrencies support the network of entry into the assets of the chosen denomination. On the other hand, one should not reject the assumption that cryptocurrencies allow for "escape" into "global digital cash" at the "retail level", for which formal restrictions on capital flows are not so fundamental. In other words, for companies operating internationally, cryptocurrencies are not a key toolkit for financial management, while restrictions on capital flows are mostly addressed by them. Similarly, such companies can circumvent regulatory barriers by reducing the importance of the formal Chinn-Ito Index.

The combination of financial development and propensity to innovate reflects the emergence of a specific segment of the financial system for which traditional approaches to assessing the investment quality of assets are not so significant. That is, based on Yermack (2015), it could be assumed that the investment demand for cryptocurrencies is unlikely to take place, and the expansion of the market boundaries of the asset portfolio should rather reflect the risk appetite. To some extent, this logic is facilitated by the data in Table 2 indicating the instability of the statistical significance of the variable financial depth itself. And the fact that investments in cryptocurrencies are becoming a new segment of global finance, despite the high volatility of their market value, just suggests that the demand for them should have specific investment features. The combination of financial development and the propensity to innovate highlights the emergence of a new class of investors who view Bitcoin ownership more as an investment in a technologically promising sector. It is this effect that allows one to see specifications (7) and (8). This discussion can be summarized by arguing that the monetary and institutional risks that lead to cryptocurrency ownership are underestimated.

\section{CONCLUSION}

Despite the obvious growing role of cryptocurrencies such as Bitcoin in the global financial industry (IMF, 2021), this paper hypothesizes that the institutional quality and inflation are key factors in determining the cross-country difference in ownership. The role of financial sector development and financial innovation as prerequisites for investment demand is also not rejected. The regression analysis used in the paper to explain the share of the population that owns Bitcoin, in general, confirms the hypotheses about the potential duality of motives, which determine why there are differences in the choice of cryptocurrency investments in different countries. First, hedging against inflation risks is the most important motive to hold Bitcoin that confirmed by the most robust connections between the independent variable and inflation proxy in all regressions' specifications. Second, hedging against institutional risks is an extremely important explanatory force. And the rule of law is the variable that demonstrated the most robustness of relationships among other quality of institutions proxies. Third, Bitcoin ownership is also driven by the need to diversify the asset portfolio, a motive generated in advanced financial systems. However, the level of financial development alone does not sufficiently explain the share of the population that owns Bitcoins across countries. Combined with the propensity to innovate, the level of financial development becomes a strong explanatory factor.

The analysis shows that there are at least three key drivers of Bitcoin ownership across countries: inflation hedge; hedge against institutional risks; the emergence of a new class of investors who not only seek to diversify assets, but also want to benefit from being involved in a segment with promising technological prospects. If the role of financial development seems to be a logical argument for the inclusion of cryptocurrencies in modern asset management strategies, the role of institutional factors per se and in the aspect of monetary weakness remains underestimated. This means that the current analysis of the nature and political economy of cryptocurrency should focus more on the institutional foundations of monetary order and the collective trust in central banks when institutions are weak. 


\section{AUTHOR CONTRIBUTIONS}

Conceptualization: Viktor Koziuk.

Data curation: Viktor Koziuk.

Formal analysis: Viktor Koziuk.

Funding acquisition: Viktor Koziuk.

Investigation: Viktor Koziuk.

Methodology: Viktor Koziuk.

Project administration: Viktor Koziuk.

Resources: Viktor Koziuk.

Writing - original draft: Viktor Koziuk.

Writing - review \& editing: Viktor Koziuk.

\section{REFERENCES}

1. AFM. (2018). Investing in cryptos in the Netherlands. Retrieved from https://www.afm.nl/ /profmedia/files/onderwerpen/cryptos/ rapport-marktonderzoek-cryptocurrencieseng.pdf

2. Aste, T. (2019). Cryptocurrency Market Structure: Connecting Emotions and Economics. Digital Finance, 1, 5-21. https://doi. org/10.1007/s42521-019-00008-9

3. Auer, R., Cornelli, G., \& Frost, J. (2020). Rise of Central Bank Digital Currency: Drivers, Approaches and Technologies (BIS Working Paper No. 88) (pp. 1-44). Retrieved from https://www.bis.org/publ/ work880.pdf

4. Bauer, D., \& McDermontt, T. (2010). Is Gold a Safe Haven? International Evidence. Journal of Banking and Finance, 34, 18861898. https://www.tcd.ie/triss/assets/PDFs/iiis/iiisdp310.pdf

5. Baur, D. G., Hong, K., \& Lee, A. D. (2018). Bitcoin: Medium of exchange or speculative assets? Journal of International Financial Markets, Institutions and Money, 54(C), 177-189. https://doi. org/10.1016/j.intfin.2017.12.004

6. Borio, C. (2019). On Money, Debt, Trust, and Central Banking (BIS Working Paper No. 763). Retrieved from https://www.bis.org/ publ/work763.htm

7. Bouri, E., Gupta, R., Tiwari, A. K., \& Roubaud, D. (2017). Does Bitcoin hedge global uncertainty? Evidence from wavelet-based quantile-in-quantile regressions. Finance Research Letters, 23(C), 87-95. https://doi.org/10.1016/j. frl.2017.02.009

8. Bouri, E., Molnár, P., Azzi, G., Roubaud, D., \& Hagfors, L. I. (2017). On the hedge and safe haven properties of Bitcoin: Is it really more than a diversifier? Finance Research Letters, 20(C), 192-198. https://doi.org/10.1016/j. frl.2016.09.025

9. Carstens, A. (2018a). Money in Digital Age: 10 Thoughts (Speech). On Lee Kuan Yew School of Public Policy, Singapore, 15 November, 2018. Retrieved from https://www. bis.org/speeches/sp181115a.htm

10. Carstens, A. (2018b). Money in Digital Age: What the Role of Central Banks (Speech). On House of Finance of Goethe University, Frankfurt, 6 February, 2018. Retrieved from https://www.bis.org/ speeches/sp180206.pdf

11. Cifuentes, A. F. (2018). Bitcoin in Troubled Economies: The Potential of Cryptocurrencies in Argentina and Venezuela. Latin American Law Review, 3, 99-116. https://doi.org/10.29263/ lar03.2019.05

12. Conover, C., Jensen, G., Johnson, R., \& Mercer, J. (2009). Can Precious Metals Make Your Portfolio Shine? The Journal of Investing, 18(1), 75-86. https://doi. org/10.3905/JOI.2009.18.1.075

13. Corbet, S., Hou, Y. G., Hu, Y., Larkin, C., \& Oxley, L. (2020). Any port in a storm: Cryptocurrency safe-havens during the COVID-19 pandemic. Economics Letters, 194(C). https://doi.org/10.1016/j. econlet.2020.109377

14. Dar, A. B., \& Maitra, D. (2017). Is gold a weak or strong hedge and safe haven against stocks? Robust evidences from three major goldconsuming countries. Applied Economics, 49(53), 5491-5503. https://doi.org/10.1080/00036846. 2017.1310998

15. Dar, A., \& Mairta, D. (2017). Is Gold a Weak or Strong Hedge and Safe Haven Against Stocks? Robust Evidence from Three Major Gold-consuming Countries. Applied Economics, 49(53), 5491-5503.

16. Dyhrberg, A. H. (2016). Hedging capabilities of bitcoin. Is it the virtual gold? Finance Research Letters, 16(C),139-144. https://doi. org/10.1016/j.frl.2015.10.025

17. FCA. (2019). How and Why Consumers Buy Cryptoassets. A Report for the FCA. Retrieved from https://www.fca.org.uk/publication/research/how-and-why-consumers-buy-cryptoassets.pdf

18. FCA. (2021). Cryptoassets Consumer Research 2021. Retrieved from https://www.fca.org.uk/ publication/research/researchnote-cryptoassets-consumerresearch-2021.pdf

19. Gomez, G. (2019). Money as an Institution: Rule versus Evolved Practice? Analysis of Multiple 
Currencies in Argentina. Journal of Risk and Financial Management, 12(2), 1-14. Retrieved from https:// repub.eur.nl/pub/116457

20. Halaburda, H., Haeringer, G., Gans, J. S., \& Gandal, N. (2020). The Microeconomics of Cryptocurrencies (NBER Working Papers No. 27477). Retrieved from https:// www.nber.org/system/files/working_papers/w27477/w27477.pdf

21. Hayo, B., \& Voigt, S. (2008). Inflation, Central Bank Independence and the Legal System. Journal of Institutional and Theoretical Economics, 164(4), 751-777. Retrieved from https:// econpapers.repec.org/article/ mhrjinste/urn_3asici_3a09324569(200812)164_3a4_5f751_3aic biat_5f2.0.tx_5f2-1.htm

22. IMF. (2021). Chapter 2: The Crypto Ecosystem and Financial Stability Challenges. (Global Financial Stability Report. Oct. 2021). Retrieved from https://www.imf. org/en/Publications/GFSR/Issues/2021/10/12/global-financialstability-report-october-2021

23. Keeper, P., \& Stasavage, D. (2003). The Limits of Delegation: Veto Players, Central Bank Independence, and the Credibility of Monetary Policy. American Political Science Review, 97(3), 593-621. https://doi.org/10.1017/ S0003055403000777

24. Kocherlakota, N. (1996). Money is Memory (Research Department Staff Report No. 218). Federal Reserve Bank of Minneapolis. Retrieved from https://www. minneapolisfed.org/research/staffreports/money-is-memory

25. Kocherlakota, N. (1998). Money is Memory. Journal of Economic Theory, 81(2), 232-251. https://doi. org/10.1006/jeth.1997.2357

26. Koziuk, V. (2021a). Confidence in digital money: Are central banks more trusted than age is matter? Investment Management and Financial Innovations, 18(1), 12-32. http://dx.doi.org/10.21511/ imfi.18(1).2021.02

27. Koziuk, V. (2021b). Willingness to adopt digital currency: whether central bank independence is important. Finance of Ukraine, 3, 7-22. https://doi.org/10.33763/ finukr2021.03.007

28. Lewis, D. (1969). Convention: a Philosophical Study. Cambridge, MA, USA: Wiley-Blackwell.

29. Lewis, D. K. (1970). Convention: A Philosophical Study. The Philosophical Quarterly, 20(80), 286-287. https://doi. org/10.2307/2218418

30. Liu, Y., \& Tsyvinski, A. (2018). Risks and Returns of Cryptocurrency (NBER Working Papers No. 24877). Retrieved from http:// www.nber.org/system/files/working_papers/w24877/w24877.pdf

31. Lyons, R., Viswanath-Natraj, G. (2020). What Keeps Stablecoins Stable? (NBER Working Papers No. 27136). Retrieved from https:// www.nber.org/system/files/working_papers/w27136/w27136.pdf

32. Mancini-Griffoli, T., Martinez Peria, M. S., Agur, I., Ari, A., Kiff, J., Popescu, A., \& Rochon, C. (2018). Casting Light on Central Bank Digital Currency (IMF Staff Discussion Notes No. 18/08). Retrieved from https://www.imf.org/ en/Publications/Staff-DiscussionNotes/Issues/2018/11/13/CastingLight-on-Central-Bank-DigitalCurrencies-46233

33. Milgrom, S., \& Stokey, N. (1982). Information, Trade and Common Knowledge. Journal of Economic Theory, 26(1), 17-27. https://doi. org/10.1016/0022-0531(82)900461

34. Miranda-Agrippino, S., \& Rey, H. (2020). U.S. Monetary Policy and the Global Financial Cycle. The Review of Economic Studies, 87(6), 2754-2776. https://doi. org/10.1093/restud/rdaa019

35. Miranda-Agrippino, S., \& Ricco, G. (2021). The Transmission of Monetary Policy Shocks. American Economic Journal: Macroeconomics, 13(3), 74-107. https://doi. org/10.1257/mac.20180124

36. Moser, P. (1999). Cheks and Balances, and the Supply of Central Bank Independence. European Economic Review, 43(8), 15691593. https://doi.org/10.1016/ S0014-2921(98)00045-2
37. Nurbayev, D. (2017). The Rule of Law, Central Bank Independence and Price Stability. Journal of Institutional Economics, 14(4), 659-687. https://doi.org/10.1017/ S1744137417000261

38. OECD. (2019). Cryptoassets in Asia. Consumer attitudes, behaviours and experiences. Retrieved from https://www.oecd.org/ finance/2019-cryptoassets-in-asia pdf

39. Panos, G. A., \& Karkkainen, T. (2019). Financial Literacy and Attitudes to Cryptocurrencies. Retrieved from https://ssrn.com/ abstract $=3482083$

40. Peterson, T. (2018). Metcalfe's Law as a Model for Bitcoin's Value. Alternative Investment Analysis Review, 7(2), 9-18. https://dx.doi. org/10.2139/ssrn.3078248

41. Reboredo, J. (2013). Is Gold a Safe Haven or a Hedge for the US Dollar? Implications for Risk Management. Journal of Banking and Finance, 37, 2665-2676. https://doi.org/10.1016/j.jbankfin.2013.03.020

42. Ritzberger-Grünwald, D., \& Stix, H. (2018). How Austrians Bank and Pay in an Increasingly Digitalized world - results from an OeNB Survey. Monetary Policy \& the Economy, Q3/18, 52-89. Retrieved from https://ideas.repec. org/a/onb/oenbmp/y2018iq318b4.html

43. Schnabel, I., \& Shin, H. S. (2004). Liquidity and Contagion: The Crisis of 1763. Journal of the European Economic Association, 2(6), 1-40. https://doi. org/10.1162/1542476042813887

44. Schnabel, I., \& Shin, H. S. (2018). Money and Trust: Lessons from the 1620s for Money in the Digital Age (BIS Working Paper No. 698). Retrieved from https://www.bis. org/publ/work698.htm

45. Smales, L. (2019). Bitcoin as a safe haven: Is it even worth considering? Finance Research Letters, 30(C), 385-393. https://doi.org/ 10.1016/j.frl.2018.11.002

46. Stylianou, K., Spiegelberg, L., Herlihy, M., \& Carter, M. (2021). Cryptocurrency Competition and 
Market Concentration in the Presence of Network Effects. Ledger, 6, 81-101. https://doi.org/10.5195/ ledger.2021.226

47. Svirydzenka, K. (2016). Introducing the New Broad-based Index of Financial Development (IMF Working Paper. WP/16/5) (pp. 1-43). Retrieved from https://www. imf.org/external/pubs/ft/wp/2016/ wp1605.pdf

48. Van Vliet, B. (2018). An Alternative Model of Metcalfe's Law for Valuing Bitcoin. Economics
Letters, 165, 70-72. https://doi. org/10.1016/j.econlet.2018.02.007

49. Vaz, J., \& Brown, K. (2020). Money Without Institutions, How Can Cryptocurrencies be Trusted? Paper presented on Financial Engineering and Banking Society Conference. Prague. Retrieved from https://www. efmaefm.org/0EFMAMEETINGS/ EFMA\%20ANNUAL\%20

MEETINGS/2020-Dublin/papers/ EFMA\%202020_stage-1301_question-Full\%20Paper_id-207.pdf
50. Yermack, D. (2015). Is Bitcoin a Real Currency? An economic appraisal. The Handbook of digital currency (NBER Working Papers No. 19747) (pp. 31-43). Retrieved from http://www.nber.org/papers/ w19747.pdf

51. Zulaica O. (2020). What Share for Gold? On the Interaction of Gold and Foreign Exchange Reserve Returns (BIS Working Paper No 906) (pp. 1-30). Retrieved from https://www.bis.org/publ/work906. pdf 